Adolescent Medicine, Mayo Clinic, Rochester, Minnesota 55905, USA. e-mails: childs.bennett@mayo.edu; vandeursen.jan@mayo.edu

1. Baker, D. J. et al. Nature 530, 184-189 (2016).

2. He, S. \& Sharpless, N. E. Cell 169, 1000-1011 (2017).
3. van Deursen, J. M. Nature 509, 439-446 (2014)

4. De Cecco, M. et al. Nature 566, 73-78 (2019).

5. Cordaux, R. \& Batzer, M. A. Nature Rev. Genet. 10 , 691-703 (2009)

6. Scott, E. C. \& Devine, S. E. Viruses 9, 131 (2017)

7. De Cecco, M. et al. Aging 5, 867-883 (2013).

8. Li, T. \& Chen, Z. J. J. Exp. Med. 215, 1287-1299 (2018).
9. Glück, S. et al. Nature Cell Biol. 19, 1061-1070 (2017).

10. Takahashi, A et al. Nature Commun. 9, 1249 (2018).

11.Brégnard, C. et al. EBioMedicine 8, 184-194 (2016).

12.Chang, J. et al. Nature Med. 22, 78-83 (2016).

13.Laberge, R.-M. et al. Nature Cell Biol. 17,

1049-1061 (2015).

\title{
Fate and future role of polar ice sheets
}

\section{Mass loss from the Greenland and Antarctic ice sheets is accelerating as a result of rising global temperatures. Two studies explore how this mass loss will affect sea level and other aspects of the climate in the future. SEE ARTICLES P.58 \& P.65}

\section{HÉLÈNE SEROUSSI}

$\mathrm{R}$ ising sea level is one of the greatest threats posed by climate change. The Greenland and Antarctic ice sheets have been losing mass at an increasing rate during the past few decades, and are the largest source of uncertainty in projections of future sea level ${ }^{1,2}$. How much these ice sheets will change over the coming decades to centuries, and how they will affect Earth's climate, remain largely unknown. Two studies now provide some answers to these questions. On page 58, Edwards et al. ${ }^{3}$ revisit estimates of the contribution of the Antarctic Ice Sheet to sealevel rise over the next few centuries. And on page 65 , Golledge et al. ${ }^{4}$ investigate how polar ice sheets affect other components of the climate system, demonstrating the ice sheets' crucial role in shaping ocean currents.

In the first study, Edwards and colleagues Antarctic ice to sea-level rise by examining a theoretical mechanism known as marine icecliff instability, which was proposed ${ }^{5}$ in 2011 and revisited ${ }^{6}$ in 2016 . The idea is that, when a floating extension of a glacier collapses, a tall ice cliff is exposed at the glacier terminus (Fig. 1). This cliff is too tall to sustain its own weight and starts to collapse rapidly, leading to further glacier retreat and mass loss.

By taking this process into account, a determine the future contribution of

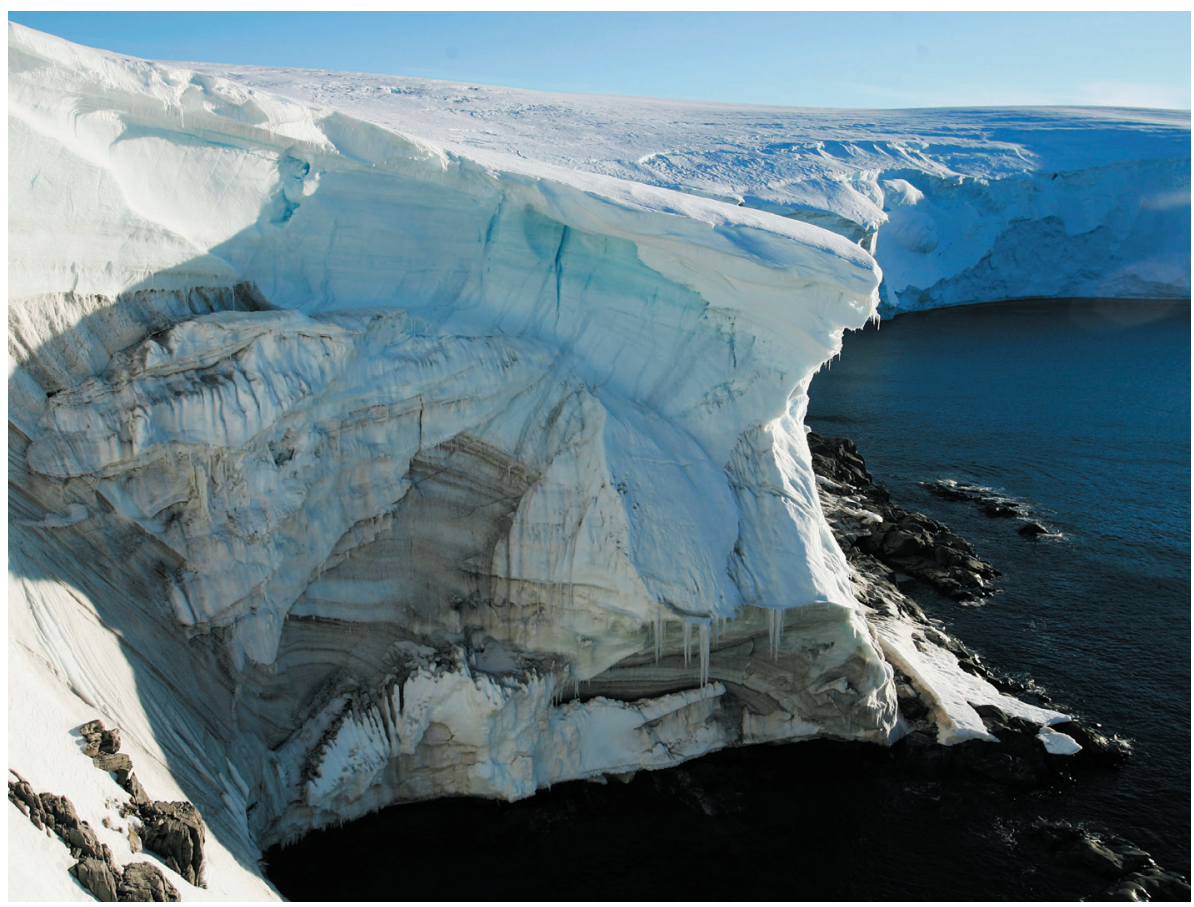

Figure 1 | An ice cliff at Landsend, Cape Denison, Antarctica. Edwards et al. ${ }^{3}$ and Golledge et al. ${ }^{4}$ investigate how mass loss from polar ice sheets will affect Earth's climate. Shown here is an ice cliff that was exposed at the terminus of a glacier when a floating extension of the glacier collapsed. numerical model predicted ${ }^{6}$ that Antarctica alone could contribute as much as one metre to sea-level rise by 2100 in a 'business as usual' scenario of carbon emissions - which assumes that little, if anything, is done to abate emissions. For comparison, other models that do not include this process estimated ${ }^{7}$ that Antarctica could contribute less than $40 \mathrm{~cm}$. Marine ice-cliff instability was first used to reconcile models of ice-sheet flow in the Antarctic with sea-level estimates in warm periods of Earth's history ${ }^{6}$. However, the mechanism has been questioned by some glaciologists, partly because it has not been directly observed and is therefore difficult to model.

Edwards et al. use emulators of complex icesheet models to run large ensembles of simulations and explore the full spectrum of model parameters. They show that, for many sets of parameters, marine ice-cliff instability is not needed to reproduce the estimated Antarctic ice loss during three past warm periods: the mid-Pliocene (about 3 million years ago), the most recent interglacial (roughly 130,000-115,000 years ago) and 1992-2017. They also find that, without this mechanism, the projected contribution of Antarctic ice to sea-level rise by 2100 agrees well with the results of previous work ${ }^{7-10}$ : a $5 \%$ chance of more than $30-40 \mathrm{~cm}$ under high-emissions scenarios and a $5 \%$ chance of more than $10-20 \mathrm{~cm}$ under low-emissions scenarios.

In the second study, Golledge and colleagues analyse the impact of the changing Greenland and Antarctic ice sheets on Earth's climate. Climate models typically include a dynamic atmosphere, ocean and sea ice, but do not consider changes in ice-sheet size and volume. Because ice sheets evolve on much longer timescales than those that govern the atmosphere or oceans, their evolution is assumed to have no effect on the other components of the climate system for simulations that cover a few centuries. As a result, ice-sheet simulations are carried out independently - with the influence of the atmosphere and oceans specified and the impact of the ice sheets on these other components is therefore neglected.

Golledge et al. investigate the validity of this approach by including changes in the release of melted ice into the oceans in a climate model. They show that the increased discharge of fresh water from the ice sheets has important consequences for ocean circulation on much shorter timescales than expected. For example, in the Northern Hemisphere, the increased amount of fresh water released by the Greenland Ice Sheet gradually slows the Atlantic Meridional Overturning Circulation - a large system of 
ocean currents that bring warm water from the tropics northwards. The deceleration leads to a $15 \%$ reduction in the simulated strength of this ocean circulation system between 2050 and 2100.

Meanwhile, in the Southern Hemisphere, the increased amount of fresh water released by the Antarctic Ice Sheet traps warm waters of the Southern Ocean beneath the sea surface. The trapped waters enhance the melting of floating ice shelves, leading to even greater ice loss from the Antarctic Ice Sheet. Including such interactions between the ice sheets and other parts of the climate system produces an increase of about $50 \%$ in the predicted amount of ice-sheet loss by 2100 , as well as a greater variability of global temperatures. These results show that ice sheets should be investigated and modelled as an integral part of the climate.

The studies by Edwards, Golledge and their respective colleagues demonstrate that polar ice sheets will have a crucial role in Earth's climate in the future, and highlight the need to explore the two-way coupling between the ice sheets and other climate components. They also emphasize the limitations on the modelling of these remote ice sheets.

For instance, current numerical models have a coarse spatial resolution that cannot capture all of the outlet glaciers in the Greenland fjords. Moreover, these models cannot accurately simulate the migration of grounding lines - the transitions between grounded ice sheets and floating ice shelves - in Antarctica. As a result, the models rely on simple parameterizations to account for such effects. Further work is needed to continue to improve numerical models and to better understand how ice sheets will affect Earth's climate over the coming decades and centuries.

\section{Hélène Seroussi is in the Sea Level and \\ Ice Group, Jet Propulsion Laboratory, \\ California Institute of Technology, Pasadena, California 91109, USA. \\ e-mail:helene.seroussi@jpl.nasa.gov}

1. Rignot, E. et al. Proc. Natl Acad. Sci. USA 116, 1095-1103 (2019).

2. van den Broeke, M. R. et al. Cryosphere 10, 1933-1946 (2016).

3. Edwards, T. L. et al. Nature 566, 58-64 (2019).

4. Golledge, N. R. et al. Nature 566, 65-72 (2019).

5. Bassis, J. N. \& Walker, C. C. Proc. R. Soc. A 468, 913-931 (2011)

6. DeConto, R. M. \& Pollard, D. Nature 531, 591-597 (2016).

7. Ritz, C. et al. Nature 528, 115-118 (2015)

8. Little, C. M., Oppenheimer, M. \& Urban, N. M. Nature Clim. Change 3, 654-659 (2013).

9. Levermann, A. et al. Earth Syst. Dyn. 5, 271-293 (2014).

10. Ruckert, K. L. et al. PLoS ONE 12, e0170052 (2017).

\section{A metabolic role for gut immune cells}

The gut is an active site of immune defence against disease-causing microbes. A study in mice shows that a type of immune cell in the gut's wall also helps to regulate sugar and fat metabolism. SEE LETTER P.115

\section{DARIA ESTERHÁZY \& DANIEL MUCIDA}

$\mathrm{T}$ The intestine has a large number of immune cells, which help to repair tissues and defend against microbial infection. The one-cell-thick lining of the gut (the intestinal epithelium) is the interface between the core of the body and the intestinal space, which is constantly exposed to food and to gut-resident and invasive microbes. The intestinal epithelium contains a type of immune cell called an intestinal intraepithelial lymphocyte (IEL). He et al. ${ }^{1}$ show on page 115 that, in addition to their immune function, IELs have a role in the control of the body's metabolism by regulating levels of a hormone that is released after food consumption.

IELs are one of the largest populations of T lymphocytes (T cells) in the body ${ }^{2}$, and provide the first line of specific immune defence against microbes in the gut. Dysregulation of
IELs causes loss of integrity of the intestinal mucosal barrier (the physical and immune barrier that surrounds the intestinal space), increased susceptibility to infections and inflammatory bowel disease ${ }^{3}$. He et al. suggested that IELs might also have a metabolic role, because these cells are abundant in the portion of the intestine where most nutrient absorption occurs, express genes associated with metabolism, constantly move along the gut epithelium even in the absence of infection, and are close to epithelial cells ${ }^{4}$.

The involvement of immune cells in the control of metabolism and in the progression of metabolic disease has been studied in other tissues. Most notably, macrophage cells and regulatory $\mathrm{T}$ cells influence metabolism in fat tissue and in blood vessels, and the function of these tissues is dysregulated in individuals with the obesity-related collection of metabolic disorders called metabolic syndrome ${ }^{5}$.

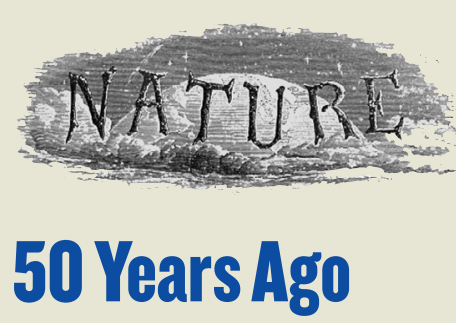

Mumiyo, a waxy substance of unknown origin found on rocks in Asia and Antarctica, was formerly thought to have healing properties, and has recently aroused considerable interest in the Soviet Union as a possible medicine ... Writing in Arbok 1967, Dr. T. S. Winsnes reports that he has seen snow petrels in the mountains of Dronning Maud Land spitting out a thick pink substance that looks very much like mumiyo ... the colour probably caused by the crustaceans which constitute most of the bird's diet. The spittle accumulates sometimes several kilos of it around the nest in the form of wax, sometimes hanging down like stalactites. Dr. Winsnes believes that this substance is the mumiyo of the Antarctic, although, of course, he cannot say whether it has a similar origin in Asia. From Nature 8 February 1969

100 Years Ago

Under the title of "The Louse Danger", the British Museum ... has issued a third "poster" in the economic series. Attention is directed ... to the danger of the clothes (or body) louse as a carrier of relapsing fever, typhus, and trench fever. In order to avoid lice, regular washing of underclothing and bed-linen is advocated. It is further desirable to avoid contact with persons suspected of being verminous; hospital workers ... are advised to wear white linen overalls ... When eggs of the louse are present in the hair, close clipping or shaving is necessary; in the case of women, washing the hair with an insecticidal solution is advised ... Simple instructions for the disinfestation of clothing and bedding are appended, together with information concerning the most useful insecticides.

From Nature 6 February 1919 